\title{
Measurement of Oxygen Atom Diffusion in Nb and Ta by Anelastic Spectroscopy
}

\author{
Luciano Henrique de Almeida ${ }^{\mathrm{a}, \mathrm{b}}$, Kelly Cristina Cezaretto Pires, \\ Carlos Roberto Grandini ${ }^{\text {b* }}$, Odila Florêncio ${ }^{\mathrm{c}}$ \\ a'Instituto de Física de São Carlos, USP, 13560-970 São Carlos - SP, Brazil \\ ${ }^{\mathrm{b}}$ Laboratório de Relaxações Anelásticas, UNESP, 17033-360 Bauru - SP, Brazil \\ 'Departamento de Física, UFSCar, 13565-905 São Carlos - SP, Brazil
}

Received: April 21, 2003; Revised: April 7, 2005

\begin{abstract}
Impurity interstitial atoms present in metals with BCC structure can diffuse in the metallic matrix by jumps to energetically equivalent crystallographic sites. Anelastic spectroscopy (internal friction) is based on the measurement of mechanical loss or internal friction as a function of temperature. Due to its selective and nondestructive nature, anelastic spectroscopy is well suited for the study of diffusion of interstitial elements in metals. Internal friction measurements were made using the torsion pendulum technique with oscillation frequency of a few $\mathrm{Hz}$, temperature interval from 300 to $700 \mathrm{~K}$, heating rate of about $1 \mathrm{~K} / \mathrm{min}$, and vacuum better than $10^{-5} \mathrm{mbar}$. The polycrystalline $\mathrm{Nb}$ and Ta samples used were supplied by Aldrich Inc. The results obtained showed thermally activated relaxation structures due to stress-induced ordering of oxygen atoms around the $\mathrm{Nb}$ (or $\mathrm{Ta}$ ) atoms of the metallic matrix. The results were interpreted by three methods and led to activation enthalpy values for the diffusion of oxygen in $\mathrm{Nb}$ and $\mathrm{Ta}$ of $1.15 \mathrm{eV}$ and $1.10 \mathrm{eV}$, respectively.
\end{abstract}

Keywords: oxygen diffusion, internal friction, interstitials, $\mathrm{Nb}, \mathrm{Ta}$

\section{Introduction}

The study of the behavior of group- $\mathrm{V}$ metals with interstitials impurities such as $\mathrm{O}, \mathrm{N}, \mathrm{C}, \mathrm{H}$ in solid solution has raised many researchers' interest, because these impurities can modify the mechanical properties of these metals ${ }^{1-3}$, for example, causing either their softening ${ }^{4}$ or hardening 5 .

The interactions of these interstitial elements with group-V metals have been largely studied by anelastic spectroscopy measurements (internal friction). The interest in studying bec metals began with Snoek's early paper ${ }^{6}$, in which he postulated a stress-induced ordering of interstitials. Atom reorientation gives rise to pronounced internal friction peaks called Snoek peaks. Such impurity reordering under the action of an applied external force and the interaction with the metallic matrix through a relaxation process is known as stress-induced ordering ${ }^{7}$. The application of this property to diffusion studies is based on the fact that a heavy interstitial atomic element such as oxygen present in a bcc lattice constitutes an elastic dipole with tetragonal symmetry and can produce anelastic relaxation.

Normally, the diffusion coefficient is measured by mass flow technique $^{8}$, but in the last thirty years, internal friction measurement has been widely recognized as a very useful technique to study diffusion phenomena in metals and alloys 9 . The discussion of diffusion phenomena in metals and alloys is centered on the fact that an interstitial atom jumps into energetically equivalent sites as a result of the application of external mechanical stress. These jumps give origin to peaks in the internal friction spectra. In general, relaxation peaks in bcc metals appear due to the presence of interstitial solute atoms and are observed as Snoek-type peaks ${ }^{7}$. The relaxation strength and the activation energy of the peaks give some information on the properties of interstitials atoms in bcc metals.

In the last twenty years, the amount of information on relaxation peaks due interstitial oxygen and nitrogen in $\mathrm{Nb}$ and $\mathrm{Ta}$ has increased sharply ${ }^{10-14}$. The positions of these peaks with respect to temperature are relatively well known, as are the activations energies and the pre-exponential factors ${ }^{11}$. Consequently, peak identification does not present a particular problem. In contrast, some arguments as to whether "clustering" and "anticlustering" occurs with increasing oxygen content ${ }^{13-19}$ have been raised. The clustering model proposes the formation of oxygen pairs and other oxygen clusters ${ }^{13}$, while the anticlustering model proposes a long-range repulsive interaction between oxygen interstitials and the possibility of some interaction between different types of heavy interstitials, such as oxygen and nitrogen ${ }^{14}$.

The purpose of this paper was to study the diffusion of oxygen atoms in $\mathrm{Nb}$ and $\mathrm{Ta}$ through anelastic spectroscopy measurements as a function of temperature using the torsion pendulum technique. The present investigation determined the activation parameters and the shape of Snoek peaks in $\mathrm{Nb}$ and $\mathrm{Ta}$ in the presence of oxygen and nitrogen using three methods of data analysis.

\section{Experimental Part}

Samples of $\mathrm{Nb}$ and $\mathrm{Ta}$ polycrystals containing oxygen and nitrogen in solid solution were investigated. The samples supplied by Aldrich Inc. had cylindrical form and $60 \mathrm{~mm}$ in length by $1 \mathrm{~mm}$ diameter, and purity of $99.8 \%$ (niobium) and $99.9 \%$ (tantalum). The chemical composition of the samples is listed in Table 1.

Anelastic relaxation measurements were made using a torsion pendulum operating with frequency between 0.3 and $10 \mathrm{~Hz}$ in the temperature range from 300 to $700 \mathrm{~K}$ in vacuum better than $10^{-5} \mathrm{mbar}$ and heating rate of about $1 \mathrm{~K} / \mathrm{min}$. The measurement principle is very simple: the sample is made oscillate in its fundamental mode, which causes energy dissipation due to internal friction. In the case of the torsion pendulum, this energy dissipation can be measured directly through the logarithmic decrement in the pendulum oscillation amplitude ${ }^{7}$. 
Data relative to the pendulum free oscillation damping are collected automatically using a laser beam reflected by a mirror placed on the pendulum that strikes two phototransistors connected to a microcomputer by a dedicated interface ${ }^{20}$.

\section{Results and Discussion}

Typical anelastic spectra for $\mathrm{Nb}$ and Ta samples are presented in Figures 1 and 2. The peaks observed in the anelastic spectrum can be associated with the interaction of oxygen atoms (main peak) and nitrogen atoms (secondary peak) with the metallic matrix, $\mathrm{Nb}$ (or Ta)-O and $\mathrm{Nb}$ (or Ta)-N, respectively. These peaks are very well known and

Table 1. Chemical composition of $\mathrm{Nb}$ and Ta samples.

\begin{tabular}{cccc}
\hline & $\mathrm{Ta}$ & \multicolumn{2}{c}{$\mathrm{Nb}$} \\
Impurity & Quantity (ppm) & Impurity & Quantity (ppm) \\
\hline $\mathrm{Cu}$ & 100 & $\mathrm{Ta}$ & 930 \\
$\mathrm{Ni}$ & 55 & $\mathrm{Ti}$ & 640 \\
$\mathrm{~V}$ & 15 & $\mathrm{Na}$ & 6 \\
$\mathrm{Cr}$ & 13 & $\mathrm{Ni}$ & 4 \\
$\mathrm{Mg}$ & 7 & $\mathrm{Mg}$ & 3 \\
$\mathrm{O}$ & 35 & $\mathrm{O}$ & 50 \\
$\mathrm{~N}$ & 25 & $\mathrm{~N}$ & 30 \\
$\mathrm{H}$ & 12 & $\mathrm{H}$ & 10 \\
\hline
\end{tabular}

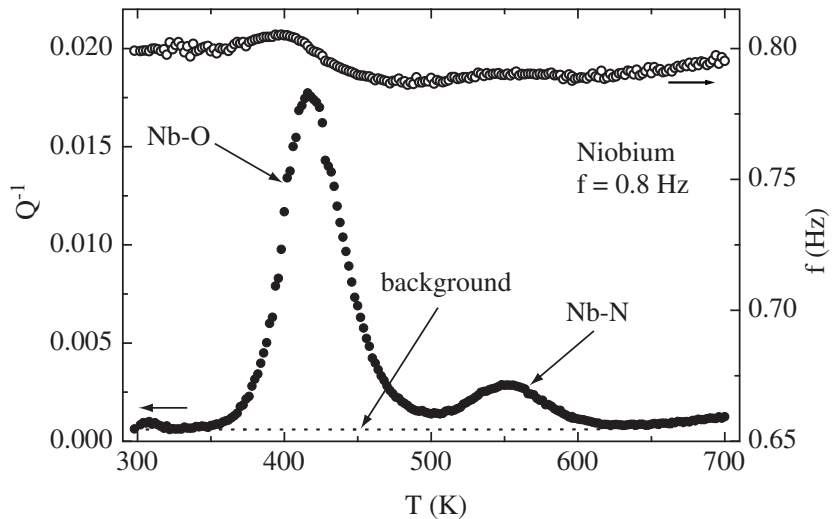

Figure 1. Anelastic relaxation spectrum of $\mathrm{Nb}$ measured with frequency of $0.8 \mathrm{~Hz}$.

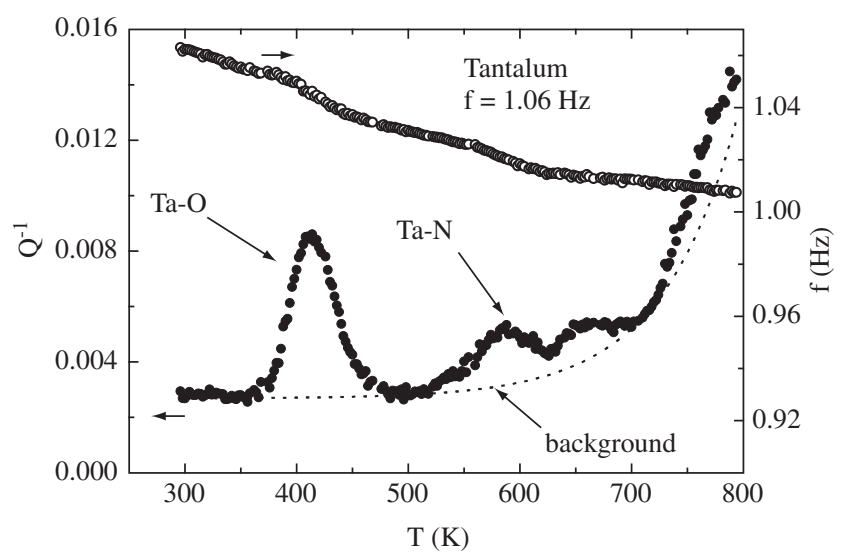

Figure 2. Anelastic relaxation spectrum of Ta measured with frequency of $1.06 \mathrm{~Hz}$. are attributed to the stress-induced ordering of oxygen and nitrogen atoms around $\mathrm{Nb}$ (or Ta) atoms in the lattice ${ }^{10-15}$. Figures 1 and 2 also show the behavior of frequency (related with the shear modulus) with temperature. The step in the peak region in the frequency curves shows that they are Snoek type. In this work, analysis will be restricted to the $\mathrm{Nb}-\mathrm{O}$ relaxation process.

Figures 3 and 4 show the influence of the oscillation frequency on the internal friction spectra for the relaxation process due to stress-induced ordering of the oxygen atoms around $\mathrm{Nb}$ (or Ta) lattice atoms. In these figures, it can observed that the relaxation structure (peak) moves to the high temperature zone with the increase in the pendulum oscillation frequency. This effect shows that the relaxation process is thermally activated.

If a single relaxation process governs the relaxation process represented by the peak in the internal friction spectrum, the basic internal friction equation is given $b^{7}$ :

$$
Q^{-1}(\omega \tau)=\Delta \frac{\omega \tau}{1+(\omega \tau)^{2}}
$$

where: $\Delta$ is the relaxation strength, $\tau$ is the relaxation time, and $\omega=$ $2 \pi \mathrm{f}, \mathrm{f}$ is the pendulum oscillation frequency.

The basic condition for the occurrence of relaxation peaks associated to a single relaxation process is:

$\omega \tau=1$

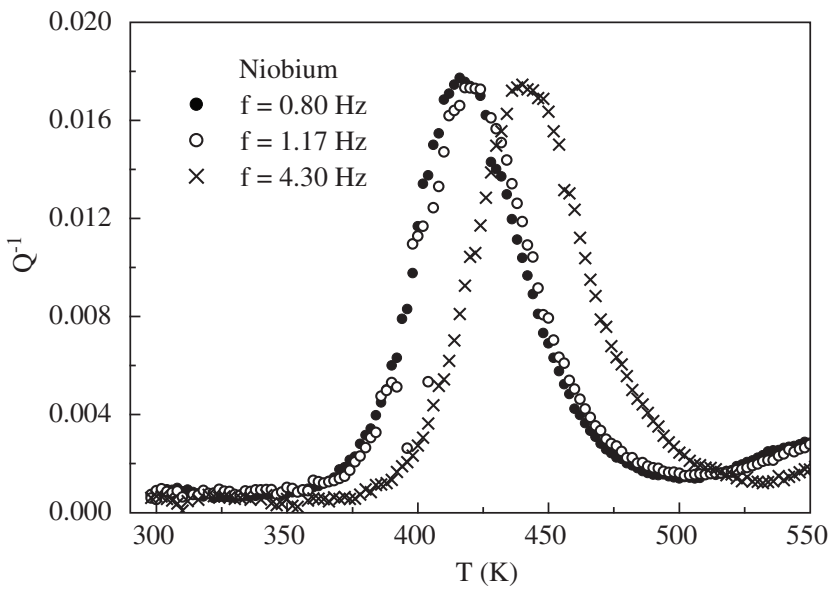

Figure 3. Frequency influence on internal friction for $\mathrm{Nb}-\mathrm{O}$ relaxation process.

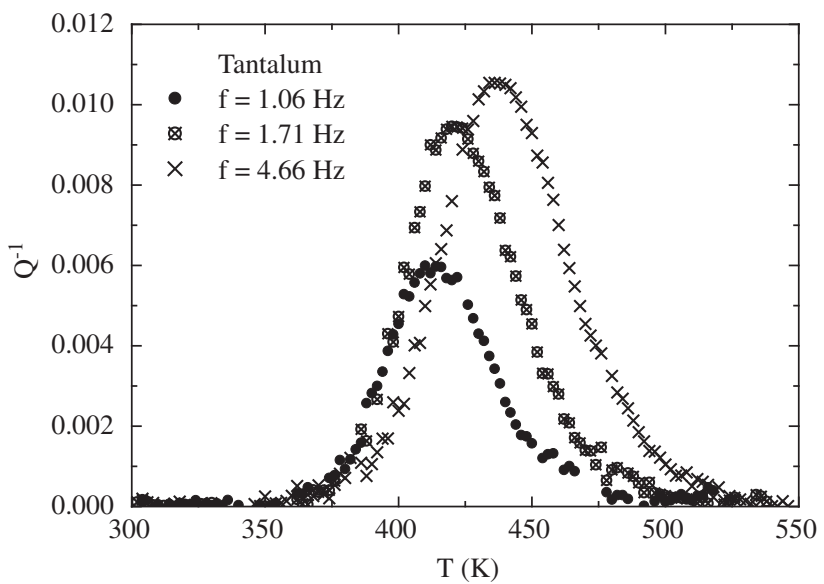

Figure 4. Frequency influence on internal friction for Ta-O relaxation process. 
Thus, the internal friction and the frequency as a function of the temperature measured in the proximity of Snoek's peak can be used to obtain information on diffusion characteristics of point defects, their thermal activation, the formation of different point defect and their redistribution under the effect of external stress. A point defect produces local distortions in the crystal, and an elastic dipole, a second order tensor, is formed ${ }^{7}$.

For a material with bcc structure, the migration of interstitial atoms is given by jumps to energetically equivalent octahedral or tetrahedral sites. The diffusion of these atoms is governed by the following expression ${ }^{7}$ :

$$
D=\frac{a_{0}^{2}}{36 \tau}
$$

where: $\mathrm{D}$ is the diffusion coefficient, $a_{0}$ is the lattice parameter, and $\tau$ is the relaxation time.

If the relaxation process is thermally activated, as is the case, the relaxation time can be written using Arrhenius' law ${ }^{7}$ :

$$
\tau=\tau_{0} \exp (H / k T)
$$

where: $\tau_{\mathrm{o}}$ is the pre-exponential factor (fundamental relaxation time of the process), $\mathrm{H}$ is the activation enthalpy, and $\mathrm{k}$ is the Boltzmann constant.

Thus, substituting Equation 4 into Equation 3, we obtain:

$$
D=D_{0} \exp \left(-\frac{H}{k T}\right)
$$

with:

$$
D_{0}=\frac{a_{0}^{2}}{36 \tau_{0}}
$$

where: $\mathrm{D}$ is the pre-exponential factor.

Applying logarithm to Equation 5, we obtain:

$$
\ln (D)=\ln \left(D_{0}\right)-\frac{H}{k T}
$$

Equation 7 shows that the logarithm of the diffusion coefficient is related with the inverse of temperature. Thus, the logarithmic graph of the diffusion coefficient as a function of the inverse of the temperature gives the activation enthalpy, $\mathrm{H}$, and the pre-exponential factor, $\mathrm{D}_{\mathrm{o}}$.

Substituting Arrhenius' law (Equation 4) in the condition of occurrence of relaxation peak (Equation 2) and applying the logarithm, it is obtained:

$$
\ln f=-\ln 2 \pi \tau_{0}-H / k T_{\mathrm{p}}
$$

where: $\mathrm{T}_{\mathrm{p}}$ is the relaxation peak temperature.

Thus, the logarithmic graph of the oscillation frequency as a function of the inverse of the temperature gives the activation enthalpy and the fundamental relaxation time of the process. Figure 5 shows the relaxation process graphs for $\mathrm{Nb}-\mathrm{O}$ and $\mathrm{Ta}-\mathrm{O}$. Using linear regression, it can be obtained the relaxation parameters above for the relaxation processes in question. These parameters are presented in Table 2.

Another methodology used to obtain the relaxation parameters of the relaxation processes above was proposed by Weller et al. ${ }^{11}$. It consists in the resolution of Equation 1 for $\tau$, that is:

$$
\tau=\frac{1}{\omega}\left[\frac{\Delta}{2 Q^{-1}} \pm \sqrt{\left(\frac{\Delta}{2 Q^{-1}}\right)^{2}-1}\right]
$$

According with Weller et al. ${ }^{11}, \Delta$ can be written as:

$$
\Delta=\frac{2 Q_{p}^{-1} T_{p}}{T}
$$

where: $\mathrm{Q}_{\mathrm{p}}^{-1}$ is the maximum internal friction, i.e., the internal friction for $\mathrm{T}_{\mathrm{p}}$.
Thus:

$$
\tau=\frac{1}{\omega}\left[\frac{Q_{p}^{-1} T_{p}}{Q^{-1} T} \pm \sqrt{\left(\frac{Q_{p}^{-1} T_{p}}{Q^{-1} T}\right)^{2}-1}\right]
$$

Figures 6 and 7 show the diffusion coefficient as a function of the inverse of the temperature for $\mathrm{Nb}$ and $\mathrm{Ta}$ samples. The pre-exponential diffusion factor of oxygen in $\mathrm{Nb}$ and $\mathrm{Ta}$ can be obtained

\begin{tabular}{|c|c|c|c|c|}
\hline Process & $\mathrm{f}(\mathrm{Hz})$ & $\mathrm{T}(\mathrm{K})$ & $\mathrm{H}(\mathrm{eV})$ & Ref. \\
\hline \multirow[t]{8}{*}{$\mathrm{Nb}-\mathrm{O}$} & & & 1.02 & $\begin{array}{l}\text { Figure } 5 \\
\text { (relaxation time) }\end{array}$ \\
\hline & & & 1.17 & $\begin{array}{l}\text { Figure } 6 \\
\text { (diffusion coefficient) }\end{array}$ \\
\hline & 0.80 & 418 & 1.15 & Figure 8 (Debye peak) \\
\hline & 2.9 & 440 & 1.15 & {$[10]$} \\
\hline & 3.5 & 442 & 1.17 & {$[15]$} \\
\hline & 1.0 & 430 & 1.15 & [17] \\
\hline & 1.3 & 430 & 1.15 & [19] \\
\hline & 6.0 & 485 & 1.15 & [22] \\
\hline \multirow[t]{5}{*}{ Ta-O } & & & 0.98 & $\begin{array}{l}\text { Figure } 5 \\
\text { (relaxation time) }\end{array}$ \\
\hline & & & 0.91 & $\begin{array}{l}\text { Figure } 7 \\
\text { (diffusion coefficient) }\end{array}$ \\
\hline & 1.06 & 414 & 1.10 & $\begin{array}{l}\text { Figure } 9 \\
\text { (Debye peak) }\end{array}$ \\
\hline & 1.0 & 421 & 1.10 & {$[10]$} \\
\hline & 1.0 & 420 & 1.10 & {$[11]$} \\
\hline
\end{tabular}
using linear regression:

$$
\begin{aligned}
& D_{\mathrm{o}}(\mathrm{Nb})=(3.17 \pm 0.02) \times 10^{-4} \mathrm{~cm}^{2} / \mathrm{s} \\
& D_{\mathrm{o}}(\mathrm{Ta})=(2.03 \pm 0.01) \times 10^{-5} \mathrm{~cm}^{2} / \mathrm{s}
\end{aligned}
$$

The activation enthalpy for these relaxation processes obtained by this methodology is presented in Table 2 .

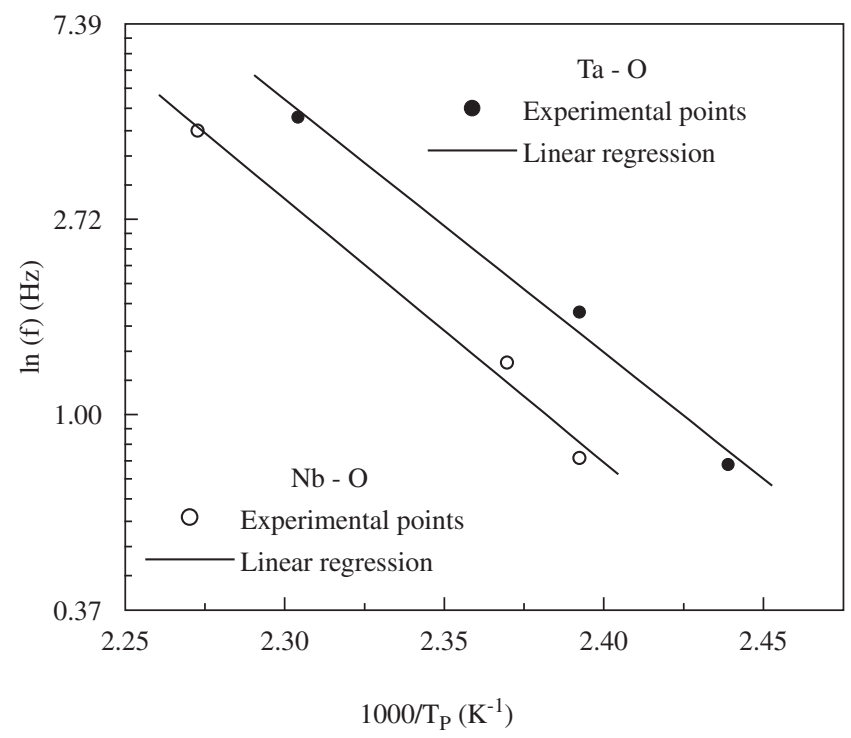

Figure 5. Frequency as a function of the inverse of the peak temperature for $\mathrm{Nb}-\mathrm{O}$ and $\mathrm{Ta}-\mathrm{O}$ relaxation processes.

Table 2. Relaxation parameters for oxygen diffusion in $\mathrm{Nb}$ and $\mathrm{Ta}$ 


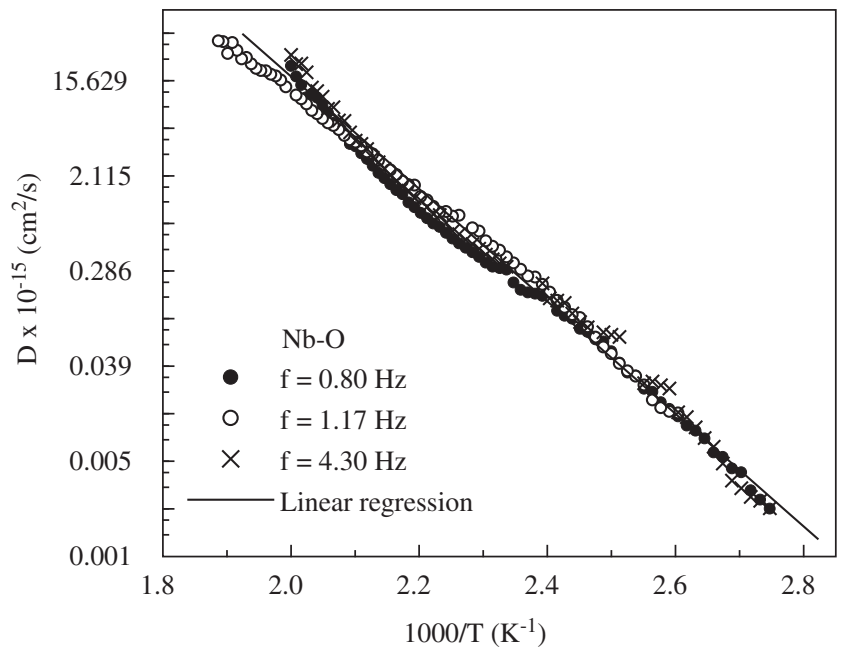

Figure 6. Diffusion coefficient as a function of the inverse of the temperature for $\mathrm{Nb}-\mathrm{O}$ relaxation process measured with frequencies of $0.80 \mathrm{~Hz}(\bullet)$, $1.17 \mathrm{~Hz}(\mathrm{o})$, and $4.30 \mathrm{~Hz}(\times)$.

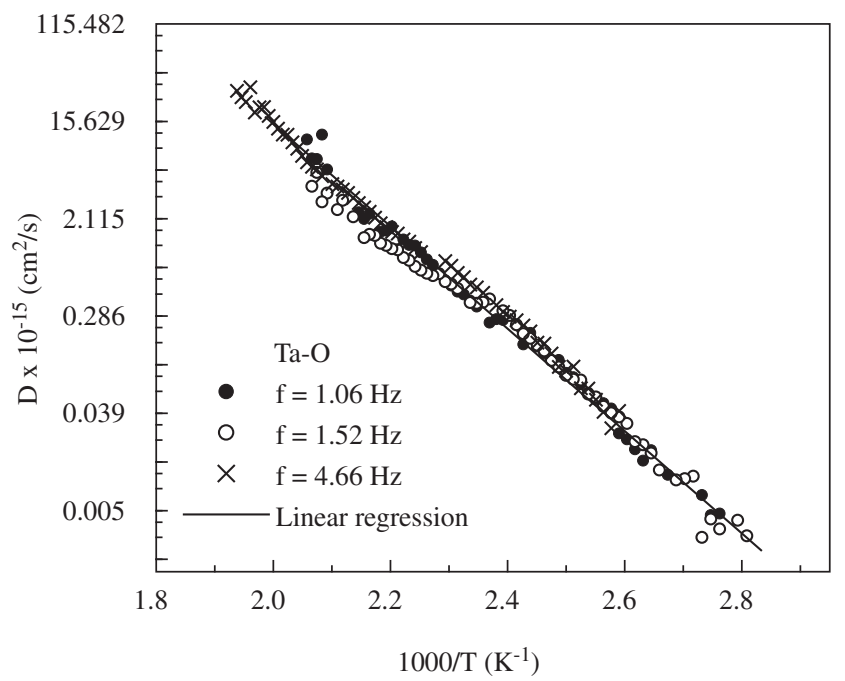

Figure 7. Diffusion coefficient as a function of the inverse of the temperature for Ta-O relaxation process measured with frequencies of $1.06 \mathrm{~Hz}(\bullet)$, $1.52 \mathrm{~Hz}(\mathrm{o})$, and $4.66 \mathrm{~Hz}(\times)$.

A third procedure consists in using the model proposed by Weller et al. ${ }^{14}$ and Equation 1 in combination with Arrhenius' law and the temperature dependence for the relaxation strength $\Delta$. In this case, the internal friction can be written as:

$$
Q^{-1}(T)=Q_{m}^{-1} \frac{T_{m}}{T} \cosh ^{-1}\left[\frac{H}{k_{b}}\left(\frac{1}{T}-\frac{1}{T_{m}}\right)+\ln \left(\frac{f(T)}{f_{m}}\right)\right]
$$

The three parameters that characterize a Debye maximum are $\mathrm{Q}_{\mathrm{m}}^{-1}$ (peak intensity), $\mathrm{T}_{\mathrm{m}}$ (peak's temperature), and $\mathrm{H}$ (activation enthalpy). These parameters can be determined by applying appropriate numerical analytical methods to the experimental data. In this paper, the Peak Fitting Modulus from Microcal Origin ${ }^{\circledR 21}$ was used.

Figures 8 and 9 show an analysis of one of the curves shown in Figures 3 and 4 based on Equation 12. The theoretical curve (full line) represents a Debye peak. The relaxation parameters are presented in Table 2 too.

The results obtained in this paper are in good agreement with data in the literature on the activation enthalpy of the relaxation

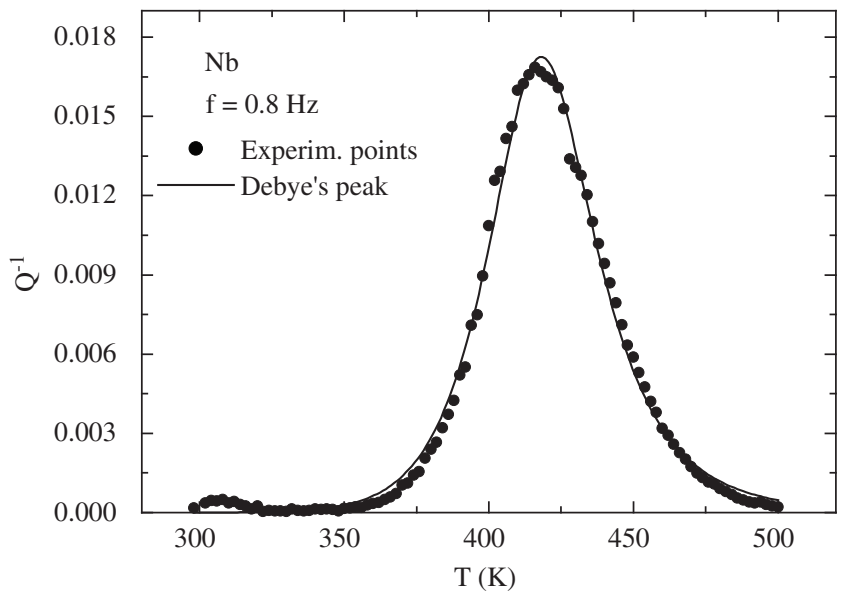

Figure 8. Internal friction as a function of temperature for $\mathrm{Nb}$ sample measured with frequency of $0.80 \mathrm{~Hz}$. The full line shows Debye's peak.

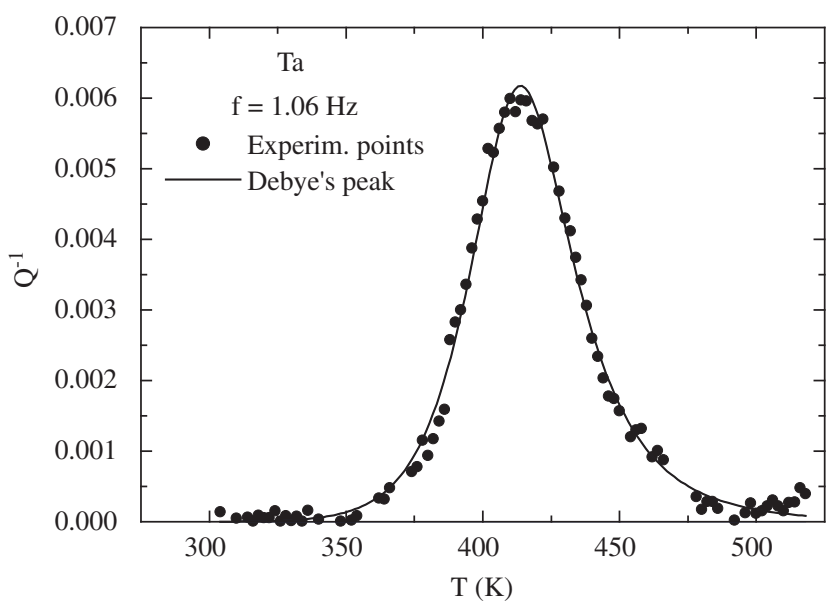

Figure 9. Internal friction as a function of temperature for Ta sample measured with frequency of $1.06 \mathrm{~Hz}$. The full line shows Debye's peak.

process due to stress-induced ordering of oxygen atoms around $\mathrm{Nb}$ and Ta atoms in metallic matrix: $1.15 \mathrm{eV}$ and $1.10 \mathrm{eV}$, respectively (vide Table 2). These results are based mainly on analysis using Debye peak-based fitting.

Among the three methods presented, analysis by Debye peakbased fitting was the most precise, because the influence of the relaxation process due to nitrogen cannot be discarded by the two other methods, frequency logarithm (Equation 8) and relaxation time (Equation 11). This occurs because the analysis is based on a single relaxation process and the presence of another relaxation process, in this case due the stress-induced ordering of nitrogen atoms, causes a broadening of the main peak.

\section{Conclusions}

Anelastic relaxation measurements of $\mathrm{Nb}$ and Ta polycrystalline samples with oxygen and nitrogen in solid solution were made.

The results showed spectra containing a relaxation peak that was 
attributed to the relaxation process due to stress-induced ordering of oxygen atoms around $\mathrm{Nb}(\mathrm{Ta})$ atoms in the metallic matrix.

The activation enthalpy and the diffusion parameter values of oxygen atoms in $\mathrm{Nb}$ and Ta obtained by three methods were $1.15 \mathrm{eV}$ and $3.17 \times 10^{-4} \mathrm{~cm}^{2} / \mathrm{s}$ for $\mathrm{Nb}$, and $1.10 \mathrm{eV}$ and $2.03 \times 10^{-5} \mathrm{~cm}^{2} / \mathrm{s}$ for Ta, respectively.

\section{Acknowledgments}

The authors would like to thank Fundação de Amparo à Pesquisa do Estado de São Paulo (FAPESP), Conselho Nacional de Desenvolvimento Científico e Tecnológico $(\mathrm{CNPq})$ and to Fundação para o Desenvolvimento da UNESP (FUNDUNESP) for the financial support.

\section{References}

1. Lundin CE, Klodt DT. The alloy systems of the group Va metals. Transactions of the ASM. 1961; 53(4):735-741.

2. Wert C. Physical acoustics. vol. 3A. New York: Academic Press; 1966.

3. Wukusick CS. Refractory metals and alloys. London: Gordon and Breach; 1967.

4. Igata N, Miyahara K, Hakomori K. Radiation anneal hardering of neutronirradiated niobium. Journal of Nuclear Science and Technology. 1979; 16(1):73-75.

5. Kubin LP. Reviews on the deformation behavior of materials. 1982; 4(3):181-275.

6. Snoek L. Effect of small quantities of carbon and nitrogen on the elastic and plastic properties of iron. Physica. 1941; 8(7):711-733.

7. Nowick AS, Berry BS. Anelastic relaxation in crystalline solids. New York: Academic Press; 1972.

8. Farraro RJ, McLellan RB. Diffusivity of oxygen and nitrogen in niobium. Materials Science and Engineering. 1978; 33(1):113-116.

9. Nowick AS. Diffusion in crystalline solids. New York: Academic Press; 1984.
10. Haneczok G, Weller M. Analysis of internal friction spectra caused by Snoek-type relaxations. Journal of Less-Common Metals. 1990; 159(3):269-276.

11. Weller M, Li GY, Zhang JX, Kê TS, Diehl J. Accurate determination of activation enthalpies associated with the stress-induced migration of oxygen or nitrogen in tantalum and niobium. Acta Metallurgica. 1981; 29(6):1047-1954

12. Indrawirawan $\mathrm{H}$, Brasche $\mathrm{LJH}$, Owen CV, Rehbein DK, Carlson ON, Peterson DT, Buck O. Internal-friction studies of the effect of hydrogen on the oxygen Snoek peaks in Va and Nb. Journal of Physics and Chemistry of Solids. 1987; 48(6):535-539.

13. Powers RW, Doyle MV. Diffusion of interstitial solutes in the group-v transition metals. Journal of Applied Physics. 1959; 30(4):514-524.

14. Weller M, Hanceczok G, Diehl J. Internal-friction studies on oxygen-oxygen interaction in niobium: 1. Experimental results and application of previous interpretations. Physics Status Solidi b. 1992; 172(1):145-159.

15. Grandini CR, Scalvi RMF, Oliveira ARG, Florêncio O, Tejima H, Jordão JAR. Estudo do efeito Snoek devido ao oxigênio em nióbio. Revista Brasileira de Física Aplicada e Instrumentação. 1995; 10(4):133-138.

16. Weller M. Anelastic relaxation of interstitial foreign atoms and their complexes with intrinsic defects in BCC metals. Journal de Physique. 1985; 46(C10):7-14.

17. Florêncio O, Botta Fo. WJ, Grandini CR, Tejima H, Jordão JAR. Anelastic behavior in NbTi alloys containing interstitial elements. Journal of Alloys and Compounds. 1994; 211-212:37-41.

18. Weller M. Anelastic relaxation of point defects in cubic crystals. Journal de Physique IV. 1996; 6(C8):63-72.

19. Grandini CR, Ferreira, LEC, Sandim, HRZ, Florêncio, O,Tejima, H, Jordão, JAR. Internal friction measurements in Nb-0.3wt.\% Ti containing oxygen. Journal de Physique IV. 1996; 6(C8):135-138.

20. Grandini CR. A Low cost automatic system for anelastic relaxation measurements. Revista Brasileira de Aplicações de Vácuo. 2002; 21(1-2):13-16.

21. Microcal Origin - Version 6. User's Manual. Northampton; 1999.

22. Niemeyer TC, Gimenez JMA, Almeida LH, Grandini CR, Florêncio O. Activation energy measurement of oxygen ordering in a nb-ti alloy by anelastic relaxation. Materials Research. 2002; 5(2):143-147. 